\title{
Gastrointestinal Trichobezoar with Long Hairy Tail (Rapunzel Syndrome)
}

\author{
Mushahid Ali ${ }^{1}$, Aadil Farooq ${ }^{2}$, Soumyodhriti Ghosh ${ }^{3 *}$, Ramnik Garg ${ }^{1}$, Rajat Agarwal ${ }^{4}$, Tanveer Alam
}

\author{
${ }^{1}$ Rashid Health Care, Prince Rd, Asalatpura, Moradabad, Uttar Pradesh 244001, India \\ ${ }^{2}$ SMS Medical College, Jawahar Lal Nehru Marg, Gangawal Park, Adarsh Nagar, Jaipur, Rajasthan 302004, India \\ ${ }^{3}$ Abhishek Child Care Hospital, Kasidih, Jamshedpur, Jharkhand 831001, India \\ ${ }^{4}$ Mohan Xrays, Lane Number 1, Gandhi Nagar, Moradabad, Uttar Pradesh 244001, India
}

DOI: $10.36347 /$ sjmcr.2020.v08i05.009

| Received: 05.05.2020 | Accepted: 12.05.2020 | Published: 16.05.2020

*Corresponding author: Soumyodhriti Ghosh

\section{Abstract}

Bezoar is an intraluminal mass formed by the accumulation of undigested material in the gastro intestinal tract. Trichobezoar is a bezoar made up of hair and is a rare cause of bowel obstruction of the proximal gastrointestinal tract (GIT). This is an uncommon entity observed mostly in young girls with trichotillomania and trichophagia. Habit pattern, personality maladjustment, mental instability, and tension have been considered as causative factors in trichophagia and symptoms are somewhat dependent on the size of mass and duration of the habit of hair eating. Various degrees of secondary anaemia are frequently observed. Symptoms in presenting patients include epigastric pain, nausea, loss of appetite and gastric outlet obstruction (GOO). I here in describe a case of giant trichobezoar that presented as gastric outlet obstruction (GOO) and was subsequently successfully removed via laparotomy.

Keywords: Gastric outlet obstruction, Bezoar, Trichobezoar, Trichotillomania, Trichophagia, Gastrointestinal tract. Copyright @ 2020: This is an open-access article distributed under the terms of the Creative Commons Attribution license which permits unrestricted use, distribution, and reproduction in any medium for non-commercial use (NonCommercial, or CC-BY-NC) provided the original author and source are credited.

\section{INTRODUCTION}

A bezoar is an intraluminal mass formed by the accumulation of undigested material in the gastrointestinal tract. It can be comprised of undigested fibres from fruit and vegetables (Phytobezoars), medications (Pharmacobezoar), undigested milk (Lactobezoar) or foreign material such as hairs (Trichobezoar). Trichobezoars are seen mostly in young females. Trichobezoar is almost always associated with trichotillomania and trichophagia and symptoms includes epigastric pain, nausea, decreased appetite and gastric outlet obstruction. Trichobezoars are a rare cause of the bowel obstruction of proximal GI tract. I here in describe a case of a gastric outlet obstruction and mass successfully removed in single piece along with its tail via laparotomy.

\section{Case Report}

13 years old girl with no previous medical illness brought to hospital with signs and symptoms of bowel obstruction. The patient complained of paroxysmal abdominal pain for last few weeks for which she was previously consulted by local doctors and took some medications but she was not relieved. Additionally the patient had weight loss, anaemia. Clinical examination revealed a palpable, nontender, firm, mobile epigastric mass extending from epigastrium down to hypogastrium. On USG abdomen a large, hard mass seen in the abdomen centrally as a thin echogenic line anteriorly and dense acoustic shadowing posteriorly, thereby totally hampering to visualise the bowel and the retroperitoneum posteriorly. CECT scan was performed to reveal a non enhancing altered density hypodense lesion in the lumen of distended stomach, into pyloric canal and upper part of duodenum (Fig-1). 

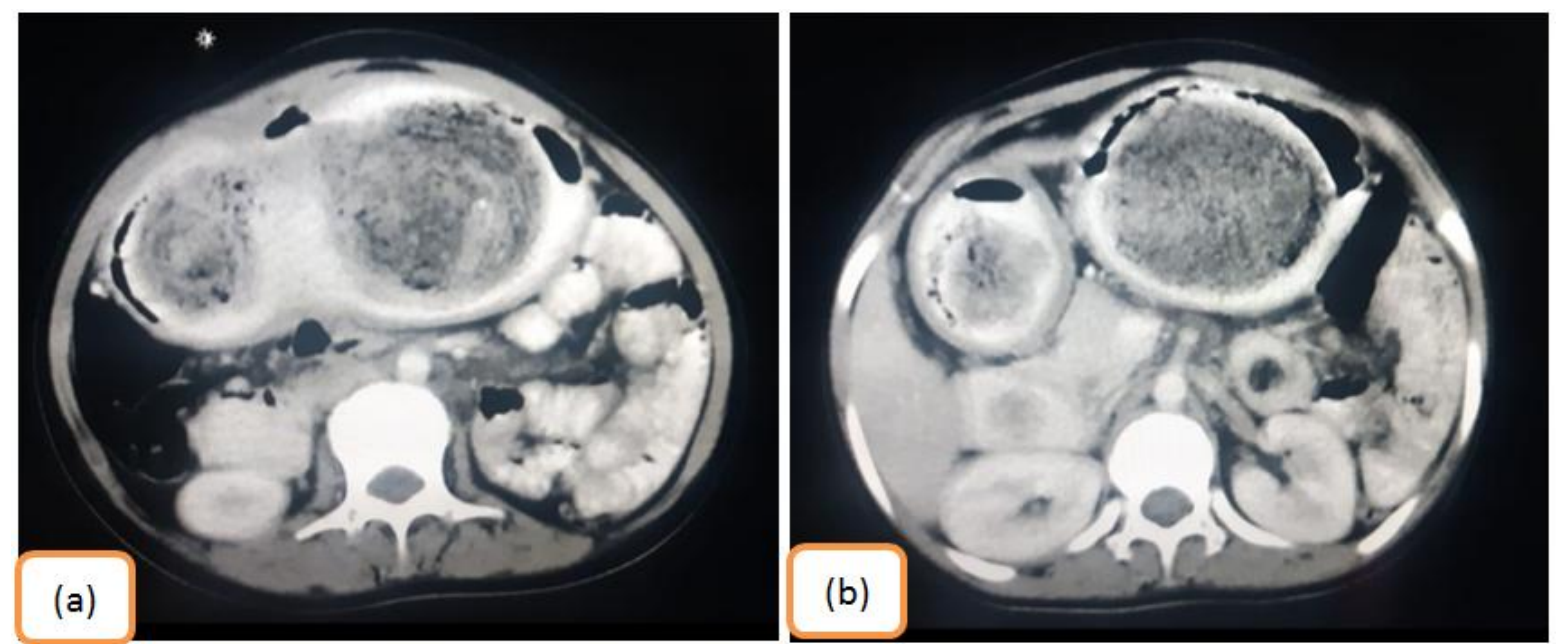

Fig-1a \& 1b: CT scan shows distended stomach, duodenum. filled with a nonenhancing altered density hypodense mass in the lumen of stomach, into pyloric canal and upper part of duodenum

Therefore, because of its bulky size, it was planned for exploratory laparotomy \& proceed. During surgery there was no fluid collection inside peritoneum. No ischemia of gut and stomach noted, but stomach was hugely distended, full with firm mass extending from fundus of stomach up to proximal jejunum. Gastrotomy was made at the fundus to expose head of trichobezoar that has assumed the shape of stomach ( $\mathbf{U}$-shaped), successfully extracted \& delivered out completely in single piece along with its tail which was going up to jejunum. The trichobezoar weighted $2.1 \mathrm{~kg}$, $\mathbf{U}$-shaped, measuring $43 \mathrm{~cm}$ long with its tail measuring around 48 cm (Fig.2). Patient's postoperative course was uneventful. 6 days later she was discharged and referred to receive psychiatric counselling.
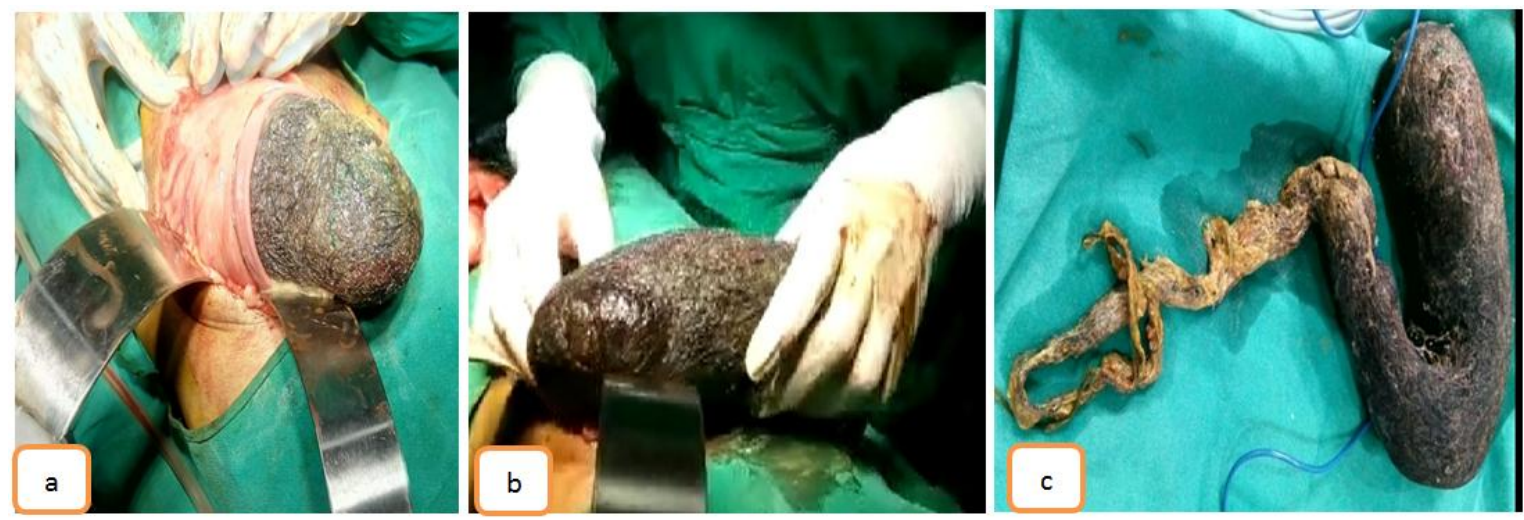

Fig 2a, 2b \& 2c: Female patient, aged 13- intraoperative photographs: giant stomach filled trichobezoar(a,b); removed huge size trichobezoar reflecting the shape of stomach along with its tail extending up to jejunum (c)

\section{DiscuSSION}

Trichobezoars are commonly associated with psychiatric disorders of trichotillomania and trichotillophagea. However trichobezoars develop in only about $1 \%$ of patients with these disorders [1]. $80 \%$ of bezoar occur before the age of 30 years and $90 \%$ occurs in females [2]. Trichobezoars are very rarely detected in young male patients [3, 4]. A well defined smooth, firm, mobile epigastric mass is found in $88 \%$ of patients and there may be tenderness in $70 \%$ of patients [5]. Usually trichobezoar develops within the stomach although locations within small intestine are also possible [3, 6]. Majority of the gastric bezoars are preoperatively diagnosed or confirmed on upper gastrointestinal study. However Stelzner is believed to have been the first to record a correct preoperative diagnosis on the basis of physical examinations in 1896
[7]. With steady improvement of x-ray techniques, identification of bezoars in the stomach has become simplified. Examination of choice is the contrast enhanced scan of upper gastrointestinal tract [3]. Ultrasound, the primary imaging modality for the evaluation of an upper abdominal mass in children, demonstrate a superficially located broad band of high amplitude echoes along the anterior wall of the mass with sharp, clean posterior acoustic shadowing [8]. Plain abdominal CT usually shows mobile intra gastric mass consisting of "compressed concentric rings "with mixed density pattern due to presence of entrapped air and food debris [9]. In our case, the bezoar, extended into the small intestine and caused symptoms of gastric outlet obstruction thus meeting the criteria of Rapunzel syndrome [10]. The Rapunzel syndrome [11] also referred as Roszpunka syndrome [12] or Raszpunka 
syndrome [13] is a rare trichobezoar extending beyond the stomach along the duodenum down to the small intestine. Bezoars are categorized into 4 main groups according to their constituting material. Phytobezoars, trichobezoars, lactobezoars \& pharmacobezoars [10]. Phytobezoars are most common accounting for $40 \%$ of all bezoars [14]. The second most common group are trichobezoars, most commonly associated with psychiatric disorders of trichotillomania (urge to pull out one's hair) and trichophagia (urge to eat one's hair). Recurrent bezoars as well as recurrent Rapunzel syndrome have been reported, most commonly in patients in whom no psychiatric treatment has been initiated $[6,15]$.

\section{Conflicts of Interest: Nil \\ Funding: Nil}

\section{REFERENCES}

1. Gonuguntla V, Joshi DD. Rapunzel Syndrome: A comprehensic review of an unusal case of Trichobezoar. Clin Med Res. 2009:7(3):99-102.

2. Dc Backey M, Ochsrer A. Bezoars and concretions. Surgery, 1939;5:132-160

3. Jain M, Solanki SL, Bhatnagar A, Jain PK. An unusual case report of rapunzel syndrome trichobezoar in a 3-year-old boy. International journal of trichology. $2011 \mathrm{Jul} ; 3(2): 102-4$.

4. Pace AM, Fearne C. Trichobezoar in a 13 year old male, a case report And reviewed of literature. Malta Medical Journal. 2003;1:39

5. Dc Backey M, Ochsrer A. Bezoars and concretions. Surgery, 1938;4:934- 963
6. Khattala K, Boujraf S, Rami M, Elmadi A, Afifi A, Sbai H, Harandou M, Bouabdallah Y. Trichobezoar with small bowel obstruction in children: two cases report. African journal of paediatric surgery. 2008 Jan 1;5(1):48-51.

7. Stelzner. Haargeschwulst in magenchirugenkonar, zentralbl chir, 1896;3:121

8. Mc Cracken S, Jongeward R, Silver TM, Jafri SZH. Gastric trichobezoar sonografic findings. Radiology, 1986;161:123-124.

9. Newman B, Girdany BR. Gastric trichobezoarssonographic and computed tomographic appearance. Pediatric Radiology. 1990 Aug 1;20(7):526-7.

10. Sanders M. Bezoars from mystical charms to medical and nutritional management practical gastroenterology. 2004; 28:37-50

11. Naik S, Gupta V, Naik S, Rangole A, Chaudhary AK, Jain P, Sharma AK. Rapunzel syndrome reviewed and redefined. Digestive surgery. 2007;24(3):157-61.

12. Mankowski P, Rolski M, Derwich K. Zespol Rapunzel-olbrzymi trichobezoar. Pediatr pol. 2006;81(10):768-70.

13. Pachana J, Szczerba D. Giant Gastro-Duodenal Trichobezoar-CT Appearance. Polish Journal of Radiology. 2004;69(4):118-20.

14. Eng K, Kay M. Gastro Intestinal bezoars: history and current treatment paradigms. Gastroenterol hepatol (NY), 2012;8(11): 776-778.

15. Memon SA, Mandhan P, Qureshi JN, Shairani AJ. Recurrent Rapunzel syndrome-a case report. Medical Science Monitor. 2003 Sep 8;9(9):CS924. 